\title{
Synthesis and Anionic Polymerization of Isocyanates Bearing a Carbamate Group
}

\author{
Katsuhiro Maeda, Mamiko Matsunaga, Hiroshi Yamada, \\ and Yoshio OKamoto ${ }^{\dagger}$ \\ Department of Applied Chemistry, School of Engineering, Nagoya University, \\ Furo-cho, Chikusa-ku, Nagoya 464-01, Japan
}

(Received August 27, 1996)

\begin{abstract}
New isocyanates bearing the carbamate group, 6-(butoxycarbonylamino)hexyl isocyanate $(n \mathrm{BAHI}), 6-((S)-$ $(+)$-s-butoxycarbonylamino)hexyl isocyanate $((+)$-BAHI $)$, and $4-((S)-(+)-s$-butoxycarbonylamino)butyl isocyanate $((+)-$ $\mathrm{BABI})$, were synthesized by reaction of a diisocyanate with an alcohol and polymerized with various anionic initiators in THF at $-98^{\circ} \mathrm{C}$. The polymerization afforded soluble polymers mainly consisting of a 1-nylon structure. The CD spectral patterns of poly $((+)$-BAHI) and poly $((+)$-BABI $)$ were similar to those of optically active helical poly(alkyl isocyanate)s, indicating that the optical rotation of poly $((+)-\mathrm{BAHI})$ and poly $((+)$-BABI $)$ is determined mainly by the prevailing helicity of the polymer chain. The chiral center in the side group separated by ten or eight $\sigma$-bonds from the polymer main chain appears to influence the helical sense of the polymer through intramolecular effect.
\end{abstract}

KEY WORDS Polyisocyanate / Anionic Polymerization / Helix / Optically Active Polymer /

Poly(alkyl isocyanate)s have been extensively studied mainly because of the stiff dynamic helical structure of polymer chains ${ }^{1}$ which gives rise to interesting properties such as liquid crystallinity ${ }^{2-5}$ and optical activities ${ }^{6-13}$ due to helicity. However, only a few studies ${ }^{14-16}$ have been done on the polymerization of isocyanates with a polar functional group, and the polymerization of isocyanates with an active hydrogen except for an acetyl group $^{15}$ has not yet been reported. Polyisocyanates with a polar side group capable of making hydrogen bonds may be important since polar interactions between the side groups may strongly influence the helical structure of a polymer chain. In the present study, we synthesized new isocyanates with a chiral carbamate group and carried out anionic polymerization with lithium initiators. The structures of the obtained optically active polymers were investigated through NMR, CD, and specific rotation measurement.<smiles>CCCCOC(=O)NCCCCCCN=C=O</smiles><smiles>CCCCCCCCCCCCCNC(=O)O[C@H](C)CC</smiles><smiles>CC[C@H](C)OC(=O)NCCCCN=C=O</smiles>

$(+)-\mathrm{BABI}$

\footnotetext{
$\dagger^{\dagger}$ To whom all correspondence should be addressed.
}

\section{EXPERIMENTAL}

\section{Materials}

Tetrahydrofuran (THF) was dried over $\mathrm{Na}$ and distilled onto $\mathrm{LiAlH}_{4}$ and distilled under high vacuum just before use. 1-Butanol and $(S)-(+)-2$-butanol $\left([\alpha]_{\mathrm{D}}+13^{\circ}\right.$, Aldrich Co.) were stirred with $\mathrm{CaH}_{2}$ overnight and distilled. 1,6-Diisocyanatohexane, $(S)-(-)$-(2-methoxymethyl)pyroridine $\left((-)\right.$-MMP) $\left([\alpha]_{\mathrm{D}}-3^{\circ}\right.$, Merck $),(R)$ $(+)$ - $N$-benzyl-1-phenylethylamine $((+)$-BPEA $)\left([\alpha]_{\mathrm{D}}\right.$ $+255^{\circ}$, Tokyo Kasei Kogyo Co.), and piperidine (Wako Co.) were stirred with $\mathrm{CaH}_{2}$ and distilled under reduced pressure. $(2 S, 3 R)-(+)-4-D i m e t h y l a m i n o-1,2-d i p h e n y l-3-$ methyl-2-butanol (Chirald) $\left([\alpha]_{\mathrm{D}}+8.2^{\circ}\right.$, Aldrich Co.) was purified by recrystallization from ethanol. Adipoyl chloride (Tokyo Kasei Kogyo Co.) and sodium azide (Kishida Co.) were used as obtained.

\section{6-(Butoxycarbonylamino)hexyl Isocyanate ( $\mathrm{BAH}$ AH)}

To a mixture of $93.6 \mathrm{~g}(0.56 \mathrm{~mol})$ of 1,6-diisocyanatohexane and $3 \mathrm{ml}$ pyridine, a solution of $40.9 \mathrm{~g}(0.55 \mathrm{~mol})$ of 1-butanol in $40 \mathrm{ml}$ of hexane was added dropwise with stirring at $70^{\circ} \mathrm{C}$ under nitrogen atmosphere. After the addition of 1-butanol, the reaction mixture was stirred under reflux for $8 \mathrm{~h}$. The solvent was removed under reduced pressure at room temperature. The residue was distilled twice under reduced pressure $\left(141^{\circ} \mathrm{C} / 0.5 \mathrm{mmHg}\right)$ to obtain pure $n \mathrm{BAHI}$. Yield: $44 \%$. IR (neat, $\mathrm{cm}^{-1}$ ): $1524(\mathrm{~N}-\mathrm{H}), 1702(\mathrm{C}=\mathrm{O}), 2272(\mathrm{~N}=\mathrm{C}=\mathrm{O}) .{ }^{1} \mathrm{H}$ NMR $\left(\delta, \mathrm{ppm}\right.$ from tetramethylsilane (TMS) in $\left.\mathrm{CDCl}_{3}\right): 0.93$ $\left(\mathrm{t}, 3 \mathrm{H}, \mathrm{CH}_{3}\right), 1.32-1.64\left(\mathrm{~m}, 12 \mathrm{H}, \mathrm{CH}_{2}\right), 3.17(\mathrm{q}, 2 \mathrm{H}$, $\left.-\mathrm{CH}_{2}-\mathrm{NH}-\right), 3.3\left(\mathrm{t}, 2 \mathrm{H},-\mathrm{CH}_{2}-\mathrm{NCO}\right), 4.06(\mathrm{t}, 2 \mathrm{H}$, $\left.-\mathrm{CH}_{2}-\mathrm{O}-\right), 4.5$ (s, $\left.1 \mathrm{H},-\mathrm{NH}-\right)$.

6-((S)-(+)-s-Butoxycarbonylamino $)$ hexyl Isocyanate $((+)-$ $B A H I)$

This monomer was prepared by the same method as above with $(S)-(+)$-2-butanol $\left(127-133^{\circ} \mathrm{C} / 0.5 \mathrm{mmHg}\right)$. Yield: $58 \%$. $[\alpha]_{365}^{25}+36^{\circ}$ (THF, $\left.c 7.8\right)$. IR (neat, $\mathrm{cm}^{-1}$ ): $1522(\mathrm{~N}-\mathrm{H}), 1702(\mathrm{C}=\mathrm{O}), 2276(\mathrm{~N}=\mathrm{C}=\mathrm{O}) .{ }^{1} \mathrm{H}$ NMR 
$\left(\delta\right.$, ppm from TMS in $\left.\mathrm{CDCl}_{3}\right): 0.83\left(\mathrm{t}, 3 \mathrm{H}, \mathrm{CH}_{3}\right), 1.1$ (d, 3H, $\left.\mathrm{CH}_{3}\right), 1.2-1.6\left(\mathrm{~m}, 10 \mathrm{H}, \mathrm{CH}_{2}\right), 3.1(\mathrm{q}, 2 \mathrm{H}$, $\left.-\mathrm{CH}_{2}-\mathrm{NH}-\right), 3.2\left(\mathrm{t}, 2 \mathrm{H},-\mathrm{CH}_{2}-\mathrm{NCO}\right), 4.5(\mathrm{~s}, 1 \mathrm{H},-\mathrm{NH}-)$, $4.6(\mathrm{q}, 1 \mathrm{H},-\mathrm{CH})$.

\section{4-((S)-(+)-s-Butoxycarbonylamino)butyl Isocyanate $((+)-$ $B A B I)$}

1,4-diisocyanatobutane was prepared by the Curtius rearrangement of acyl azide as reported previously. ${ }^{17}$ $(+)$-BABI was synthesized in the same way as for $n \mathrm{BAHI}$ using 1,4-diisocyanatobutane and $(S)-(+)$-2-butanol $\left(111-115^{\circ} \mathrm{C} / 0.2 \mathrm{mmHg}\right.$ ). Yield: $52 \%$. $[\alpha]_{365}^{25}+40^{\circ}$ (THF, c 10). IR (neat, $\left.\mathrm{cm}^{-1}\right): 1533(\mathrm{~N}-\mathrm{H}), 1702(\mathrm{C}=\mathrm{O}), 2268$ $(\mathrm{N}=\mathrm{C}=\mathrm{O}) .{ }^{1} \mathrm{H} \operatorname{NMR}\left(\delta\right.$, ppm from TMS in $\left.\mathrm{CDCl}_{3}\right)$ : $0.9\left(\mathrm{t}, 3 \mathrm{H}, \mathrm{CH}_{3}\right), 1.2\left(\mathrm{~d}, 3 \mathrm{H}, \mathrm{CH}_{3}\right), 1.47-1.67(\mathrm{~m}, 10 \mathrm{H}$, $\left.\mathrm{CH}_{2}\right), 3.2\left(\mathrm{q}, 2 \mathrm{H},-\mathrm{CH}_{2}-\mathrm{NH}-\right), 3.3\left(\mathrm{t}, 2 \mathrm{H},-\mathrm{CH}_{2}-\mathrm{NCO}\right)$, $4.5(\mathrm{~s}, 1 \mathrm{H},-\mathrm{NH}-), 4.7(\mathrm{q}, 1 \mathrm{H},-\mathrm{CH})$.

\section{Polymerization and Oligomerization Procedure}

Polymerization was carried out in a glass ampule provided with a three-way stopcock under a dry $\mathrm{N}_{2}$ atmosphere. A monomer and THF were placed in the ampule with a syringe and the solution was cooled to $-98^{\circ} \mathrm{C}$. The initiator solution prepared by mixing equimolar tert-butyllithium and amine or alcohol in THF at room temperature was added to the monomer solution with a syringe. The polymerization was terminated by adding ten fold excess $\mathrm{HCl}$ in methanol to the initiator. The polymeric products were precipitated in excess methanol- $\mathrm{H}_{2} \mathrm{O}$, collected with a centrifuge, and dried in vacuo at room temperature overnight.

Oligomerization was carried out in the same way as the polymerization above. After termination, the solvent was evaporated and the residue was dissolved in $\mathrm{CHCl}_{3}$. The solution was washed with water and the chloroform layer was dried over magnesium sulfate. Chloroform was then removed to recover the oligomers.

\section{Measurement}

Optical rotation was measured using a JASCO DIP181 polarimeter. Circular dichroism (CD) spectra were taken on a JASCO J-720L spectrometer. IR spectra were recorded on a JASCO FT/IR-7000 infrared spectrometer. NMR spectra were taken with a Varian VXR-500 $(500 \mathrm{MHz})$ spectrometer. FD mass spectra were taken using a JEOL JMS-AX505HA instrument. The molecular weights of the polymers were estimated by GPC measurement with a Shodex GPC SYSTEM-21 chromatograph equipped with a DAWN DSP light-scattering detector on a Shodex KF-806L and a Shodex KF-803 columns connected in series using THF as the eluent at $40^{\circ} \mathrm{C}$.

Fractionation of the oligomer was done using a JASCO 880-PU chromatograph equipped with a JASCO 875UV (UV) and a Shodex OR-1 (polarimeter) detectors.

\section{RESULTS AND DISCUSSION}

$n \mathrm{BAHI}$ was synthesized by reaction of 1,6-diisocyanatohexane and 1-butanol, and unreacted diisocyanate and dicarbamate formed were removed completely by distillation under reduced pressure.

Table I shows the results of polymerization of $n \mathrm{BAHI}$ in THF at $-98^{\circ} \mathrm{C}$. Lithium amide of piperidine (Piperidine-Li) was used as the achiral initiator. As chiral initiators, lithium amides of $(-)$-MMP $((-)$-MMP-Li) and $(+)$-BPEA $((+)$-BPEA-Li) and lithium alkoxide of Chirald (Chirald-Li) were examined. These chiral

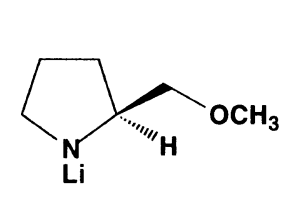

(-)-MMP-Li<smiles>C[C@H](NCc1ccccc1)c1ccccc1</smiles>

(+)-BPEA-Li<smiles>CC(C)C[C@H](C)[C@](Cc1ccccc1)(O[Ga])c1ccccc1</smiles>

Chirald-Li

initiators afforded optically active polymers in the polymerization of alkyl and aromatic isocyanates. ${ }^{18-20}$ In all runs, polymers soluble in THF and $\mathrm{CHCl}_{3}$ were obtained in good yields. Figure 1 shows the ${ }^{1} \mathrm{H}$ NMR spectra of $n \mathrm{BAHI}(\mathrm{A})$ and poly $(n \mathrm{BAHI})(\mathrm{B})$ obtained with (-)-MMP-Li. $n$ BAHI shows a sharp triplet centered at $3.3 \mathrm{ppm}$ which can be assigned to the methylene protons attached to the isocyanate group, while poly$(n \mathrm{BAHI})$ gave a broad signal centerd at about $3.7 \mathrm{ppm}$ assigned to the protons. The ${ }^{1} \mathrm{H}$ NMR spectrum of poly(butyl isocyanate) showed a broad signal of the $\mathrm{CH}_{2}$ group adjacent to the main chain nitrogen. ${ }^{21}$ The broadening was due to lack of mobility of the main chain. These results indicate that the obtained poly$(n \mathrm{BAHI})$ has mostly the 1-nylon structure. However, polymers obtained with the optically active initiators showed no optical activity. This is in contrast to the

Table I. Polymerization of $n \mathrm{BAHI}$ with various initiators in $\mathrm{THF}$ at $-98^{\circ} \mathrm{C}^{\mathrm{a}}$

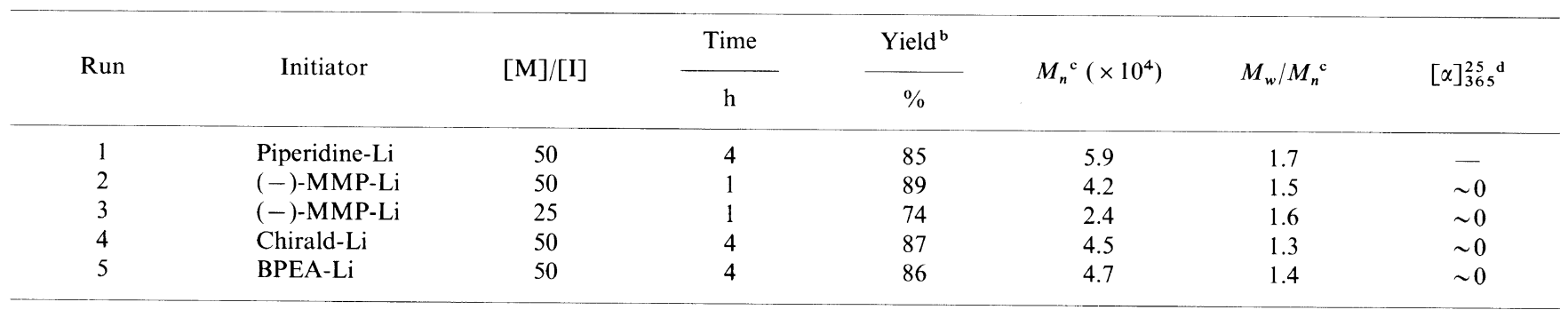

${ }^{\mathrm{a}}$ Conditions: monomer $0.5 \mathrm{~g}$, THF $5 \mathrm{ml} .{ }^{\mathrm{b}}$ Methanol- $\mathrm{H}_{2} \mathrm{O}(9: 1)$ insoluble part. ${ }^{\mathrm{c}}$ Determined by light-scattering method. ${ }^{\mathrm{d}} \mathrm{In} \mathrm{CHCl}_{3}$. 
(B)
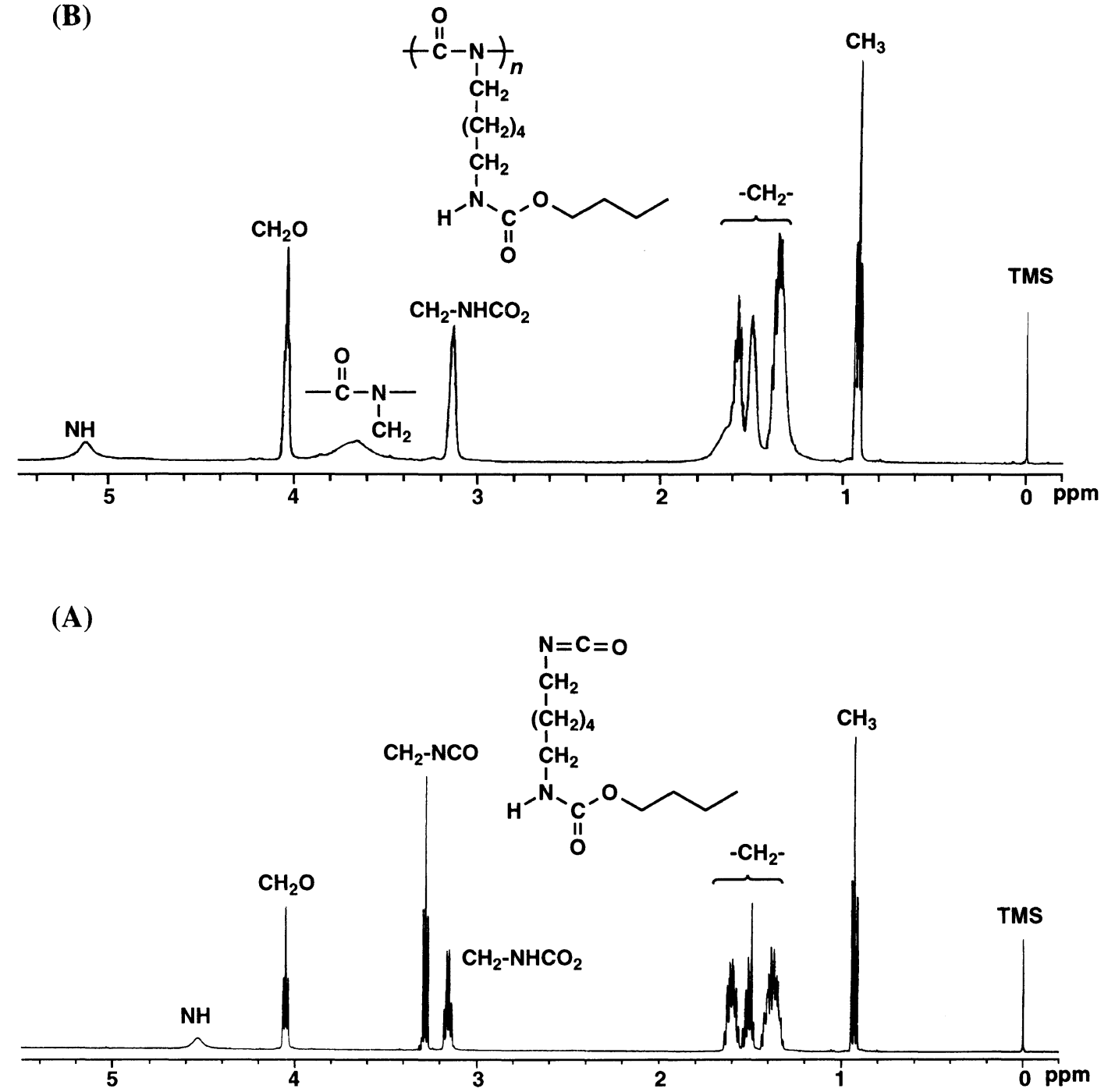

Figure 1. ${ }^{1} \mathrm{H}$ NMR spectra of $n \mathrm{BAHI}(\mathrm{A})$ and poly $(n \mathrm{BAHI})$ (run 2 in Table I) (B) in $\mathrm{CDCl}_{3}$ at $60^{\circ} \mathrm{C}(500 \mathrm{MHz})$.

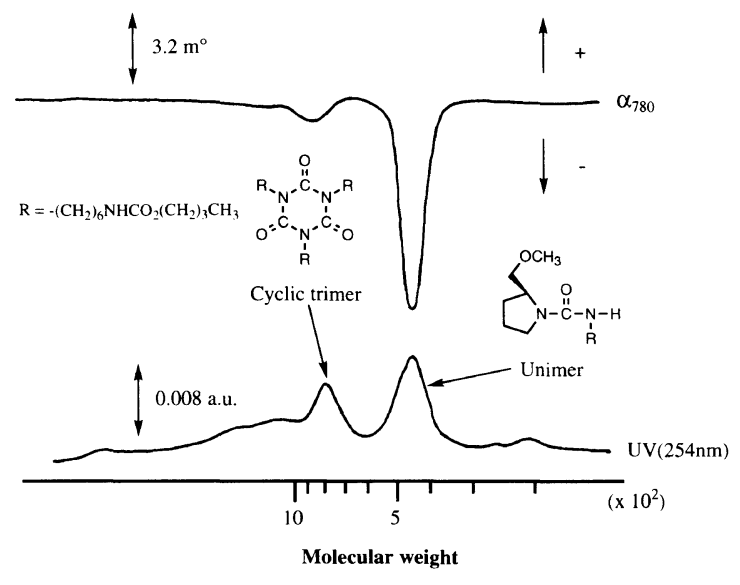

Figure 2. GPC curves of oligo $(n \mathrm{BAHI})$ measured with polarimeter $(780 \mathrm{~nm})$ and UV $(254 \mathrm{~nm})$ detectors.

results for the polymerization of alkyl and aromatic isocyanates with some chiral initiators, ${ }^{18-20}$ from which we obtained optically active polymers. The chiral initiator residues introduced at the initial polymer chain end $(\alpha$-end) through initiation reaction induced the prevailing helical structure of the polymer chain. To examine whether $\operatorname{poly}(n \mathrm{BAHI})$ contains a chiral fragment attach-<smiles>CCCCOC(=O)NCCCCCCNC(=O)O</smiles>

Propagation End Transfer to Carbamate Group

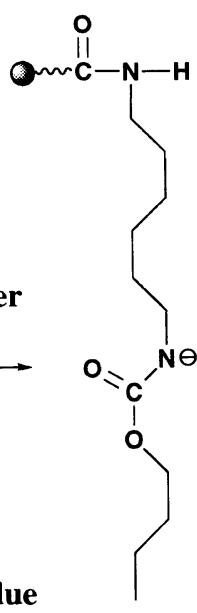

Scheme 1.

ed to the $\alpha$-end, oligomerization with (-)-MMP-Li was carried out. Figure 2 shows the GPC curve of the obtained oligomers. Two main peaks were fractionated by GPC and assigned to a unimer having a chiral initiator residue and cyclic trimer as indicated in Figure 2, based on ${ }^{1} \mathrm{H}$ NMR data. FD mass spectroscopic data of low molecular weight oligomers indicated that the polymers 
Table II. Polymerization of (+)-BAHI and (+)-BABI in THF at $-98^{\circ} \mathrm{C}^{a}$

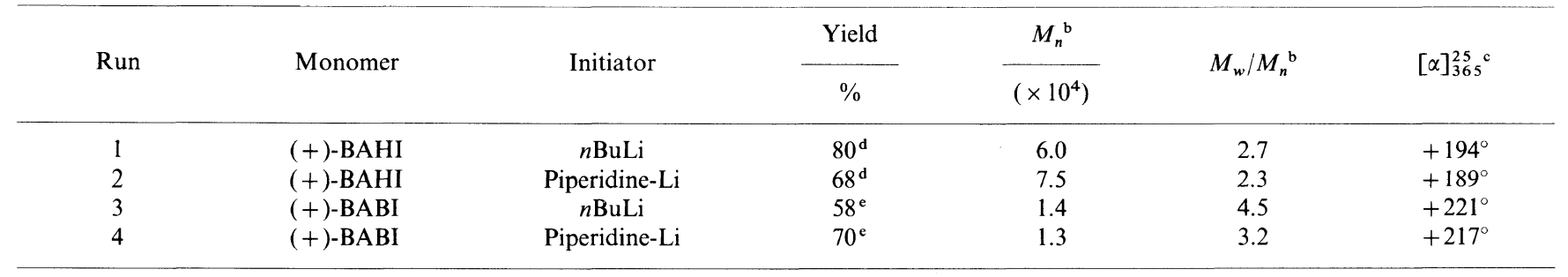

${ }^{\mathrm{a}}$ Conditions: monomer $0.5 \mathrm{~g}$, THF $5 \mathrm{ml}, 4 \mathrm{~h},[\mathrm{M}] /[\mathrm{I}]=50 .^{\mathrm{b}}$ Determined by light-scattering method. ${ }^{\mathrm{c}}$ In $\mathrm{THF} .{ }^{\mathrm{d}} \mathrm{Methanol}-\mathrm{H}_{2} \mathrm{O}(9: 1)$ insoluble part. ${ }^{\mathrm{e}}$ Methanol- $\mathrm{H}_{2} \mathrm{O}(2: 1)$ insoluble part.

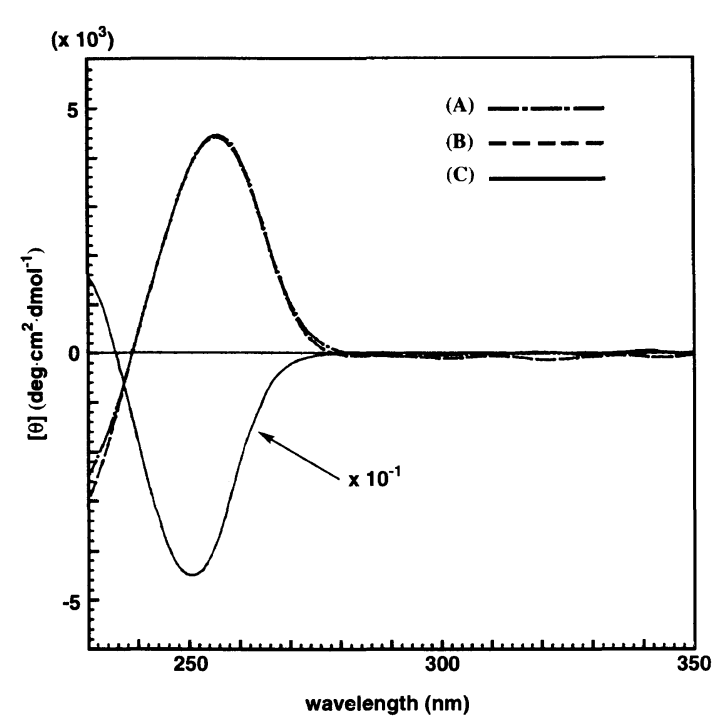

Figure 3. CD spectra of poly $((+)-\mathrm{BAHI}$ ) (run 2 in Table II) (A), poly $((+)$-BABI) (run 4 in Table II) $(\mathrm{B})$, and poly $((R)-2,6$-dimethylheptyl isocyanate) $\left(M_{w}=7.4 \times 10^{4}, M_{n} / M_{w}=2.5,[\alpha]_{\mathrm{D}}^{25}-475^{\circ}\right)(\mathrm{C})$.

obtained with the optically active initiators probably contained a chiral fragment attached to the $\alpha$-end. However, the oligomers of higher molecular weight show no optical rotation. Transfer of the propagation end to the carbamate group in the initial stage of the polymerization as shown in Scheme 1 is the reason for this. The chiral fragment attached to the $\alpha$-end after the transfer may not twist the polymer chain in one direction. Such a transfer does not seem to take place intermolecularly because the obtained polymers were soluble in $\mathrm{CHCl}_{3}$ and THF and had a relatively narrow molecular weight distribution.

Table II shows the results of the polymerization of $(+)$-BAHI $\left([\alpha]_{365}^{25}+36^{\circ}\right)$ and $(+)$-BABI $\left([\alpha]_{365}^{25}+40^{\circ}\right)$ with achiral initiators in THF at $-98^{\circ} \mathrm{C}$. $n$-BuLi and lithium amide of piperidine were used as initiators. The obtained polymers showed much larger optical rotations than the monomers. To clarify the conformations of these optically active polymers, CD spectra were measured in THF (Figure 3). Poly ((+)-BAHI) and poly $((+)-B A B I)$ showed almost identical CD spectra and were mirror images of poly $((R)-2,6 \text {-dimethylheptyl isocyanate })^{22}$ possessing a prevailing helical structure. ${ }^{11,12}$ The CD intensity of the polymers was about one tenth the latter polymer. The chiral monomers showed no CD bands at wavelengths greater than $230 \mathrm{~nm}$. These results indicate that these polymers have prevailing helical structures, of the screw sense which is opposite that of poly $((R)-2,6-$ dimethylheptyl isocyanate $)^{2}$ with predominantly right-

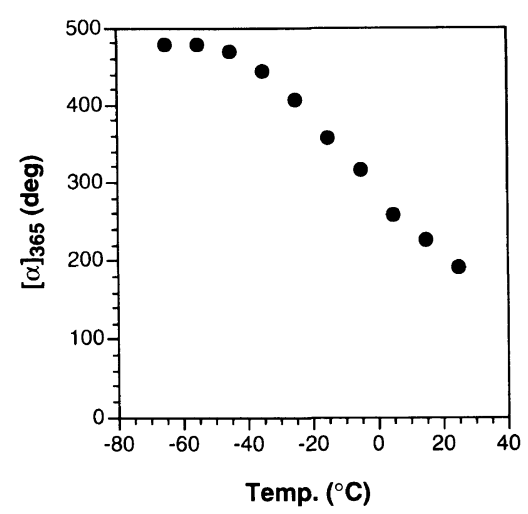

Figure 4. Specific rotations of poly $((+)-\mathrm{BAHI})$ (run 2 in Table II) in THF at various temperatures.

handed helicity.

The specific rotation of poly $((+)$-BAHI) (run 2 in Table II) in THF was measured at various temperatures and the results are shown in Figure 4. The specific rotation of the polymer greatly increased with decrease in temperature and this change was reversible. The analogous temperature dependence of specific rotation has been observed for other optically active polyisocyanates with helical structure. ${ }^{7-9}$ The optical rotation of poly $((+)$-BAHI) and poly $((+)$-BABI $)$ would thus appear to be determined mainly by the prevailing helicity of a polymer chain.

Table III shows the results of the copolymerzation of $(+)$-BAHI with achiral $n$-butyl isocyanate $(n \mathrm{BuI})$ with piperidine- $\mathrm{Li}$ in THF at $-98^{\circ} \mathrm{C}$. The compositions of the obtained copolymers were determined by ${ }^{1} \mathrm{H}$ NMR. The CD absorption intensity of the copolymers is plotted against $n \mathrm{BuI}$ composition in Figure 5. The CD absorption intensity of the copolymers steeply decreased with decrease of the $(+)$-BAHI component and that of the copolymer containing $50 \%$ chiral monomer was less than one third that of the $(+)$-BAHI homopolymer. Continuous $(+)$-BAHI sequences may thus more efficiently induce a one-handed helical structure. Polar interactions between adjacent (+)-BAHI side groups may more efficiently induce the helical conformation.

In poly $((+)$-BAHI $)$ and poly $((+)-B A B I)$, chiral centers in the side group are separated by ten and eight $\sigma$-bonds, respectively, from each polymer main chain and this may be too far to permit strong influence on the screw sense of the polymer chain. Therefore, it is anticipated that the influence of chiral centers on helical sense may derive from intermolecular interaction. To confirm this, CD measurements of poly(hexyl isocyanate) and poly $(n \mathrm{BAHI})$ (run 1 in Table I) were made in the 
presence of the optically active dicarbamate $1\left([\alpha]_{365}^{25}\right.$ $\left.+53^{\circ}\right)$ a by-product in the synthesis of $(+)$-BAHI.<smiles>CC[C@H](C)OC(=O)NCCCCCCNC(=O)O[C@@H](C)CC</smiles>

1

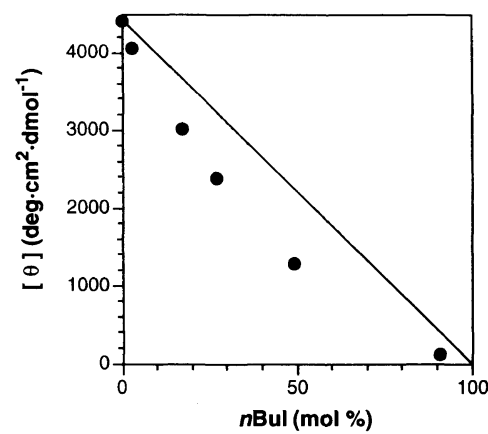

Figure 5. Plots of $\mathrm{CD}$ absorption intensity $v s$ composition ratio of poly $((+)-\mathrm{BAHI}-c o-n \mathrm{BuI})$ in THF.
Neither system showed CD bands due to main chain helicity even in the presence of a hundred times molar quantity of the dicarbamate to the monomeric residues of the polymers. These results suggest that the chiral centers in the side group separated by ten or eight $\sigma$-bonds from the polymer main chain may influence the helical sense of the polymers through intramolecular interactions. Green et al. found a very tiny chiral sterical effect due to the differences between hydrogen and deuterium to induce the prevailing helical structure for poly(alkyl isocyanate)s. ${ }^{7-10}$

Figure 6 shows GPC curves of poly $((+)$-BAHI) (run 2 in Table II) and poly $((+)-B A B I)$ (run 4 in Table II). Poly $((+)$-BAHI) showed a unimodal pattern, whereas poly $((+)$-BABI) a bimodal pattern. The higher-molecular-weight and lower-molecular-weight fractions of poly$((+)-\mathrm{BABI})$ were separated by GPC. The CD spectral patterns of the two fractions were almost the same except for intensity, indicating that optical rotations are determined primarily by the prevailing helicity of the main chain. The reason why only $(+)$-BABI gave a polymer with bimodal molecular weight distribution is not clear. The results of GPC analysis with a polarimeter detector indicate that the fraction of higher-molecular-weight has

Table III. Copolymerization of (+)-BAHI $\left(\mathrm{M}_{1}\right)$ and $n \mathrm{BI}\left(\mathrm{M}_{2}\right)$ with Piperidine- $\mathrm{Li}$ in THF at $-98^{\circ} \mathrm{C}^{\mathrm{a}}$

\begin{tabular}{|c|c|c|c|c|c|c|}
\hline \multirow{2}{*}{ Run } & \multirow{2}{*}{$\begin{array}{c}{\left[\mathrm{M}_{1}\right] /\left[\mathrm{M}_{1}+\mathrm{M}_{2}\right]} \\
\quad \text { in feed } / \%\end{array}$} & \multirow{2}{*}{$\frac{\text { Yield }^{\mathrm{b}}}{\%}$} & \multirow{2}{*}{$\frac{\left[\mathrm{M}_{1}\right] /\left[\mathrm{M}_{1}+\mathrm{M}_{2}\right]^{\mathrm{c}}}{\%}$} & \multirow{2}{*}[\alpha]{$_{365}^{25}{ }^{d}$} & \multirow{2}{*}{$M_{n}^{\mathrm{e}}\left(\times 10^{4}\right)$} & \multirow{2}{*}{$M_{w} / M_{n}{ }^{\mathrm{e}}$} \\
\hline & & & & & & \\
\hline 1 & 100 & 74 & 100 & +189 & 7.5 & 2.3 \\
\hline 2 & 91 & 63 & 96 & +184 & 6.6 & 2.2 \\
\hline 3 & 82 & 67 & 83 & +152 & 5.5 & 2.7 \\
\hline 4 & 71 & 56 & 73 & +136 & 4.8 & 2.3 \\
\hline 5 & 49 & 54 & 51 & +79 & 5.1 & 2.3 \\
\hline 6 & 10 & 33 & 9 & +11 & 2.8 & 2.1 \\
\hline
\end{tabular}

${ }^{a}$ Monomer $1.0 \mathrm{~g}$, THF $5 \mathrm{ml},[\mathrm{M}] /[\mathrm{I}]=50,4 \mathrm{~h} .{ }^{\mathrm{b}} \mathrm{MeOH}-\mathrm{H}_{2} \mathrm{O}(9: 1)$ insoluble part. ${ }^{\mathrm{c}}$ Estimated by ${ }^{1} \mathrm{H}$ NMR. ${ }^{\mathrm{d}}$ In THF. ${ }^{\mathrm{e}}$ Determined by light-scattering method.

(A)

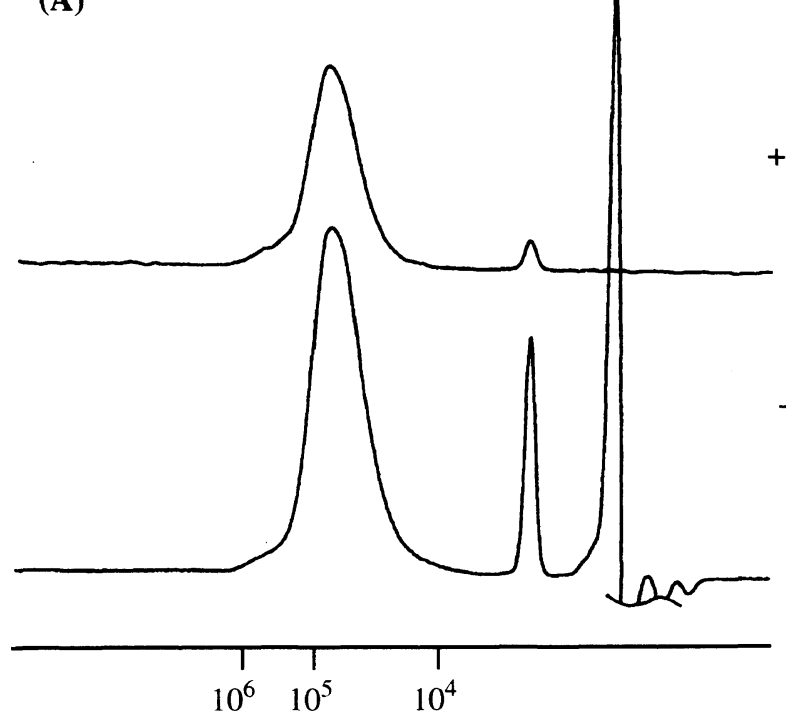

Molecular weight
(B)

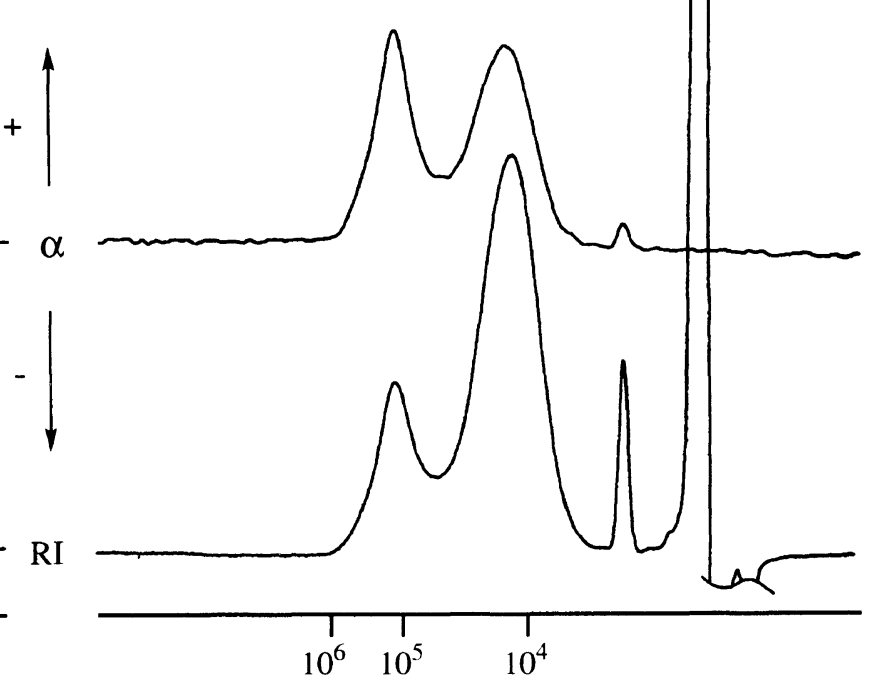

Molecular weight

Figure 6. GPC curves of poly((+)-BAHI) (run 2 in Table II) (A) and poly((+)-BABI) (run 4 in Table II) (B) measured with polarimeter and RI detectors. 
nearly three times the optical activity of the fraction of lower-molecular-weight. The higher-molecular-weight fraction is not due to association of the polymer because the lower one always gave a unimodal peak in GPC measurement. The optical activity may increase with molecular weight of the polymer as reported for poly(alkyl isocyanate). ${ }^{7-9}$

In conclusion, the anionic polymerization of the isocyanates with a carbamate group afforded polymers mainly having the 1-nylon structure. The polymerization of $(+)$-BAHI and (+)-BABI with achiral initiators gave the optically active polymers, whose optical rotation was determined mainly by the prevailing helicity of the main chain. Chirality situated at more than ten $\sigma$-bonds from the polymer main chain seems to affect the helical sense of the polymer.

Acknowledgment. We are grateful to Professor Mark M. Green of Polytechnic University for his discussions and advices.

\section{REFERENCES AND NOTES}

1. A. J. Bur and L. J. Fetters, Chem. Rev., 76, 727 (1976).

2. M. M. Green, N. C. Peterson, T. Sato, A. Teramoto, R. Cook, and S. Lifson, Science, 268, 1860 (1995).

3. S. M. Aharoni, Macromolecules, 12, 94 (1979)

4. T. Sato, Y. Sato, Y. Umemura, A. Teramoto, Y. Nagamura, J. Wagner, D. Weng, Y. Okamoto, K. Hatada, and M. M. Green, Macromolecules, 26, 4551 (1993).
5. T. Itou and A. Teramoto, Macromolecules, 21, 2225 (1988).

6. M. Goodman and S. Chen, Macromolecules, 13, 398 (1970)

7. M. M. Green, C. Peterson, C. Andreola, and S. Lifson, J. Am. Chem. Soc., 111, 8850 (1989).

8. A. Teramoto, T. Sato, Y. Nakamura, H. Gu, M. M. Green, C. Andreola, N. C. Peterson, and S. Lifson, Macromolecules, 28, 1016 (1995).

9. A. Teramoto, T. Sato, Y. Nakamura, H. Gu, F. Mukaida, N. Okamoto, M. M. Green, C. Andreola, N. C. Peterson, and S. Lifson, Macromolecules, 29, 2878 (1996).

10. M. M. Green, C. Andreola, B. Muñoz, and M. Reidy, J. Am. Chem. Soc., 110, 4063 (1988).

11. M. M. Green and M. Reidy, J. Am. Chem. Soc., 111, 6452 (1989).

12. M. M. Green, B. A. Garetz, B. Muñoz, and H. Chang, J. Am Chem. Soc., 117, 4181 (1995).

13. M. M. Green, C. Khatri, and N. C. Peterson, J. Am. Chem. Soc., 115, 4941 (1993).

14. K. Liou, K. C. Khemani, and F. Wudl, Macromolecules, 24, 2217 (1991).

15. C. A. Khatri, M. M. Vaidya, K. Levon, S. K. Jha, and M. M. Green, Macromolecules, 28, 4719 (1995).

16. M. Müller and R. Zentel, Macromolecules, 29, 1609 (1996).

17. C. F. H. Allen and A. Bell, Org. Synth., III, 846 (1955).

18. Y. Okamoto, M. Matsuda, T. Nakano, and E. Yashima, J. Polym. Sci., A, Polym. Chem., 32, 309 (1994).

19. Y. Okamoto, M. Matsuda, T. Nakano, and E. Yashima, Polym. J., 25, 391 (1993).

20. K. Maeda, M. Matsuda, T. Nakano, and Y. Okamoto, Polym. J., 27, 141 (1995).

21. M. M. Green, R. A. Gross, C. Crosby, III, and F. C. Schilling, Macromolecules, 20, 992 (1987).

22. The polymer was prepared by the polymerization of $(R)-2,6$ dimethylheptyl isocyanate with $\mathrm{NaCN}$ in toluene at $-78^{\circ} \mathrm{C}$ $\left(M_{w}=7.4 \times 10^{4}, M_{w} / M_{n}=2.5,[\alpha]_{\mathrm{D}}^{25}-475^{\circ}\right)$. 